\title{
PD-L1 expression in malignant salivary gland tumors
}

\author{
Koji Harada*, Tarannum Ferdous and Yoshiya Ueyama
}

\begin{abstract}
Background: Programmed death-1 ligand-1 (PD-L1) an important cancer biomarker that can suppress the immune system and its high expression is often reported to be related with increased tumor aggressiveness in some cancers. Here, we examined and evaluated PD-L1 expression in patients with malignant salivary gland tumor. Moreover, the relationship between PD-L1 immunolocalization and clinical pathological features, as well as the prognosis of malignant salivary gland tumors was investigated.

Methods: We examined PD-L1expression in 47 patients with malignant salivary gland tumor by immunohistochemical staining. PD-L1 positivity was defined as $\geq 5 \%$ in tumor cell membrane and evaluated according to three categories $(0 \%=0,<5 \%=1, \geq 5 \%=2)$ in tumor-infiltrating mononuclear cells (TIMCs). Fisher's exact test was used to compare between PD-L1 expression and clinico-pathological features, and Kaplan-Meier method was used to estimate the distribution of OS by PD-L1 positivity.

Results: PD-L1 expression was detected in 51.1\% of malignant salivary gland tumor tissues. No association was observed between PD-L1 immunolocalization in tumor and patient gender, or age. However, PD-L1 immunodetection of tumor cell membranes was significantly associated to stage, recurrence or metastasis after surgery, and patient outcome. On the other hand, PD-L1 immunodetection of tumor-infiltrating mononuclear cells (TIMCs) was significantly associated to recurrence or metastasis after surgery, and patient outcome. PD-L1 positivity in both tumor cell membrane and TIMCs was associated with shorter overall survival (OS) ( $p=0.002$ and $p=0.016$, respectively).
\end{abstract}

Conclusion: These findings suggested that patients with PD-L1 positive tumors or TIMCs appear to have poor clinical outcomes in malignant salivary gland tumors.

Keywords: PD-L1, Malignant salivary gland tumor, Prognosis, Immunohistochemistry

\section{Background}

The incidence of malignant salivary gland tumors is relatively low compared to other head and neck cancers. They account for more than $0.5 \%$ of all malignancies and approximately $3-6.5 \%$ of all head and neck cancers $[1,2]$. These tumors show varied histological features, and are largely present in the parotid and submandibular glands. The standard treatment for salivary gland cancers is surgical operation because they show resistance to chemotherapy and radiotherapy generally; however, its treatment often requires complex multidisciplinary approach $[3,4]$. We often select post-operative radiotherapy when the tumor could not be removed

\footnotetext{
* Correspondence: harako@yamaguchi-u.ac.jp

Department of Oral and Maxillofacial Surgery, Yamaguchi University Graduate School of Medicine, 1-1-1 Minamikogushi, Ube 755-8505, Japan
}

completely by surgery [5]. Unfortunately, these are the only treatment options currently available for malignant salivary gland tumors. As these tumors are often slow growing and are detected at an advanced, non-surgical stage; sometimes they are difficult to treat. Conventional chemotherapies often shows poor efficacy in managing locally advanced or metastatic tumors $[3,4,6]$. Molecular targeted therapies might be useful for the treatment of these patients, although no significant guidelines or tools for selecting candidate patients are available [7]. Thus, novel therapeutic strategies need to be developed and established for the treatment of malignant salivary gland tumors.

It is well known that development and prognosis of malignant tumors are closely associated with host immune functions. Anti-tumor immune responses are 
induced when the host immune system efficiently identifies the tumor antigen and various $\mathrm{T}$ cells are activated. Co-stimulatory molecules and regulative networks play an important role in this progression. There are two groups of co-stimulatory molecules: the tumor necrosis factor TNF receptor (TNFr) superfamily and the immunoglobulin (Ig) superfamily [8]. Programmed death-1 (PD-1) is a co-stimulatory molecule that functions as an immune checkpoint. It is expressed on T cells and pro- $\mathrm{B}$ cells, and negatively regulates $\mathrm{T}$ cell activation and responses [9]. Two binding ligands have been identified for PD-1, Programmed death-1 ligand-1 (PD-L1, also known as B7-H1) and PD-L2, and both belong to the B7 family $[10,11]$. PD-L1 is expressed in resting $\mathrm{T}$ cells, $\mathrm{B}$ cells, dendritic cells (DCs) and in various tumor cells; and the formation of PD-1 and PD-L1 receptor-ligand complex leads to the inhibition of the cytotoxic $\mathrm{T}$ cells and induces special apoptosis of T cells, which results in tumor immune escape [12-14]. Moreover, it has been reported that overexpression of PD-L1 is closely associated with the poor prognosis of renal cell carcinoma, esophageal cancer, gastric cancer, urothelial cancer, pancreatic cancer, and malignant melanoma [12, 15-19]. However, the levels and clinical significance of PD-L1 expression in malignant salivary gland tumor is still unknown.

The purpose of our study was to characterize the PDL1 expression in patients with malignant salivary gland tumor, and to investigate the relationship between PDL1 expression levels with clinico-pathological features as well as disease outcomes of the patients.

\section{Methods}

\section{Patients and samples}

Institutional review board (IRB) of the ethical committee of the Yamaguchi University Hospital approved this study (Ref H26-179). Our study was a retrospective one; therefore, informed consent was waived by the IRB.

Forty-seven patients $(n=47)$ with salivary gland cancers (Adenoid cystic carcinoma, Mucoepidermoid carcinoma, Adenocarcinoma and Mucinous adenocarcinoma) treated surgically at Yamaguchi University Hospital from April 1990 to March 2011 were included in this study. Clinicopathological characteristics such as gender, age, stage and follow-up data (recurrence, metastasis and outcome) were retrospectively collected from patients' medical records.

\section{Immunohistochemistry}

Tissue samples obtained from biopsy or operation specimens were used to prepare Formalin-Fixed ParaffinEmbedded (FFPE) blocks. Four-micron-thick tumor sections were prepared from these blocks were used for the immunohistochemical analysis. These paraffin-embedded tissue sections were deparaffinized in 100\% xylene (Wako
Pure Chemical Industries, Ltd.) for $10 \mathrm{~min}$ at room temperature, followed by rehydration using graded (100$70 \% v / \mathrm{v}, 5 \mathrm{~min} /$ each concentration) ethyl alcohol (Muto Pure Chemicals Co., Ltd., Tokyo, Japan). Then, the sections were washed with phosphate-buffered saline (PBS), and heated in a microwave in a Tris-EDTA buffer solution ( $\mathrm{pH}$ 9.0). The slides were then allowed to cool down, and inserted into a $0.3 \%$ hydrogen peroxide/methanol mixture for $20 \mathrm{~min}$ at room temperature. After PBS wash, the tissue sections were incubated with Dako REAL ${ }^{\mathrm{Tm}}$ Peroxidase-Blocking solution (Agilent Technologies, Inc., Santa Clara, CA, USA) for $30 \mathrm{~min}$ at room temperature; then incubated overnight at $4{ }^{\circ} \mathrm{C}$ with a rabbit polyclonal anti-PD-L1 antibody (Abcam, Cambridge, UK). After PBS wash, Dako REAL ${ }^{\mathrm{Ts}}$ EnVision $^{\mathrm{Tm}}$ Detection system (Agilent Technologies) was used according to the manufacturer's protocol to detect the immunostaining. Tissues were then lightly counterstained with hematoxylin (Muto Pure Chemicals Co., Tokyo, Japan), and were subsequently dehydrated in graded $(70-100 \% \mathrm{v} / \mathrm{v})$ ethyl alcohol (Muto Pure Chemicals Co., Ltd.), inserted in xylene (Wako Pure Chemical Industries Ltd.) and mounted with glass coverslips using DPX mounting medium (Sigma-Aldrich; Merck $\mathrm{KGaA})$. In case of negative controls, primary antibody was omitted.

\section{Quantification of PD-L1 expression in tumor cell membrane}

Immunoreactivity for PD-L1 expression was evaluated in tumor cell membrane by three authors $(\mathrm{KH}, \mathrm{TF}$, and $\mathrm{YU})$, who had no knowledge of the patient's clinical status. Briefly, five randomly selected areas were examined. The proportion of tumor cells showing high and low immunolabeling in each selected field was determined by counting individual tumor cells at high magnification $(\times 400)$. At least 200 tumor cells were counted. PD-L1 tumor positivity was defined as $\geq 5 \%$ tumor cell membrane staining. PD-L1-positive immunolabeling was predominantly located in the cytoplasm and with some nuclear membrane localization (Fig. 1).

\section{Quantification of PD-L1 expression in tumor-infiltrating mononuclear cells}

The extent of tumor-infiltrating mononuclear cells (TIMCs) (i.e. lymphocytes and macrophages) was assessed in hematoxylin and eosin-stained slides and evaluated as absent (0), focal (1), mild (2), moderate (3) and marked (4) by three authors (KH, TF, and YU), who had no knowledge of the patient's clinical status. The percentage of PD-L1-positive TIMCs was also evaluated independently. Immunoreactivity for PD-L1 expression was evaluated according to three categories $(0 \%=0,<5 \%=1, \geq 5 \%=2)$. An adjusted score representing PD-L1 expression was calculated multiplying the percentage of TIMCs that stained 

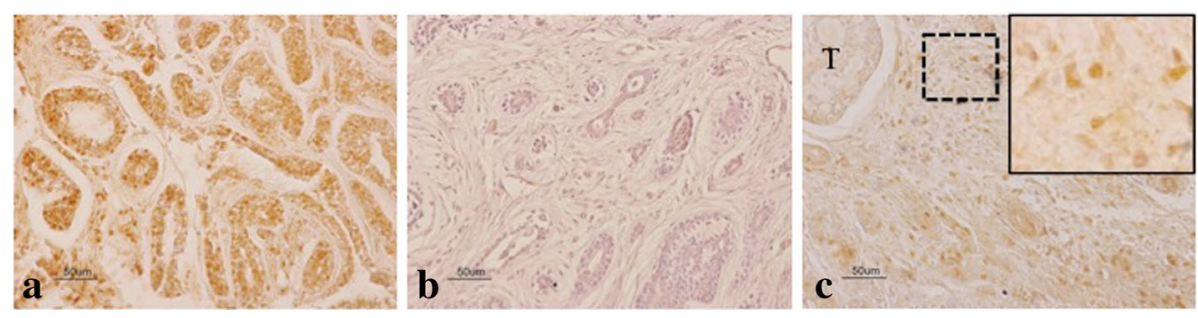

Fig. 1 PD-L1 expression in FFPE samples stained with anti-PD-L1 antibody. a Positive staining is present in tumor cells membrane. b Negative staining is present in tumor cells membrane. c Tumor cells are negative (T) and TIMCs are positive for PD-L1, magnified view of TIMCs was shown in the upper right corner

positive for PD-L1 and the extent of mononuclear cell infiltration.

\section{Statistical analysis}

In the present study, we investigated PD-L1 expression and its association with clinical outcome in patients with malignant salivary gland tumor. Overall survival (OS) defined as time from diagnosis to death was analyzed as an end point. In the absence of an event, the end point was censored at last follow-up time. Patient and tumor characteristics were summarized descriptively. PD-L1 positivity was defined as $5 \%$ or greater of tumor cell membrane staining. For PD-L1 expression in TIMCs, any score greater than five was considered high. Comparisons between PD-L1 expression and clinicopathological features were evaluated using Fisher's exact test for categorical variables. Kaplan-Meier method estimated the distribution of OS by the PD-L1 positivity. All statistical computations were carried out using the StatView software (version 5.0 J, SAS Institute Inc. Cary, NC, USA) and a $p$ value (two-sided) $<0.055$ was considered statistically significant.

\section{Results}

\section{Patients and tumor characteristics}

Characteristics of 47 patients with malignant salivary gland tumor included in this study are summarized in Table 1. The histological subtypes included adenoid cystic carcinoma $(n=25)$, mucoepidermoid carcinoma $(n=9)$, adenocarcinoma $(n=11)$ and mucinous adenocarcinoma $(n=2)$. The median follow-up time was 7.4 years [interquartile range (IQR): $1.8-12.8$ ], and the median age was 62 years (range $24-80$ years). For malignant salivary gland tumor, clinical stages I, II, III and IV at diagnosis was identified in 9, 18, 5 and 15 patients, respectively.

\section{PD-L1 expression in tumor cells and clinico-pathological features}

Table 2 shows the association between PDL- 1 expression in tumor cell membrane and clinico-pathological features of patients. Among 47 patients with malignant salivary gland tumor, 23 patients (48.9\%) showed negative PD-L1 expression in tumor cell membrane; whereas 24 patients (51.1\%) showed positive expression. Specifically, PD-L1 positivity in tumor cell membrane was detected in 11 of $25(44.0 \%)$ adenoid cystic carcinoma patients, 7 of $11(63.6 \%)$ mucoepidermoid carcinoma patients, 5 of 9 (55.6\%) adenocarcinoma patients, and 1 of 2 (50.0\%) mucinous

\section{Table 1 Patient characteristics}

\begin{tabular}{|c|c|c|}
\hline Characteristic & Total $(n=47)$ No. of patients & $\%$ \\
\hline \multicolumn{3}{|l|}{ Gender } \\
\hline Male & 26 & 55.3 \\
\hline Female & 21 & 44.7 \\
\hline \multicolumn{3}{|l|}{ Stage } \\
\hline 1 & 9 & 19.1 \\
\hline$\|$ & 18 & 38.3 \\
\hline III & 5 & 10.6 \\
\hline IV & 15 & 31.9 \\
\hline \multicolumn{3}{|l|}{ Histology } \\
\hline adenoid cystic carcinoma & 25 & 40.4 \\
\hline mucoepidermoid carcinoma & 9 & 17.0 \\
\hline adenocarcinoma & 11 & 23.4 \\
\hline mucinous adenocarcinoma & 2 & 6.4 \\
\hline \multicolumn{3}{|c|}{ Recurrence or metastasis after surgery } \\
\hline No & 31 & 66.0 \\
\hline Yes & 16 & 34.0 \\
\hline \multicolumn{3}{|c|}{ PD-L1 expression in tumor cells membrane } \\
\hline$<5 \%$ (negative) & 23 & 48.9 \\
\hline$\geq 5 \%$ (positive) & 24 & 51.1 \\
\hline \multicolumn{3}{|c|}{ PD-L1 expression in tumor-infiltrating mononuclear cells (TIMC) } \\
\hline Score $<4$ (negative) & 27 & 57.4 \\
\hline \multirow[t]{2}{*}{ Score $\geq 4$ (positive) } & 20 & 42.6 \\
\hline & Median & Min-max \\
\hline Age (years) & 62.0 & $24-80$ \\
\hline
\end{tabular}


Table 2 Association between PD-L1 expression in malignant salivary gland tumor membrane and clinico-pathological factors $^{\text {a }}$

\begin{tabular}{|c|c|c|c|c|}
\hline \multirow[t]{2}{*}{ Characteristic } & \multicolumn{2}{|c|}{$\%$ Positive tumor cell membrane } & \multirow[b]{2}{*}{$\begin{array}{l}\text { Total } \\
(n=47), n\end{array}$} & \multirow[t]{2}{*}{$p$-value } \\
\hline & $\begin{array}{l}<5 \% \text { (negative) } \\
(n=23,48.9 \%), n\end{array}$ & $\begin{array}{l}5 \% \text { or more } \\
\text { (positive) } \\
(n=24,51.1 \%), n\end{array}$ & & \\
\hline \multicolumn{3}{|l|}{ Gender } & & $>0.999$ \\
\hline Male & 13 & 13 & 26 & \\
\hline Female & 10 & 21 & 21 & \\
\hline \multicolumn{4}{|l|}{ Age } & $>0.999$ \\
\hline $65 \geq$ & 13 & 12 & 25 & \\
\hline $65<$ & 10 & 12 & 22 & \\
\hline \multicolumn{4}{|l|}{ Stage } & 0.047 \\
\hline $\mid+\|$ & 17 & 10 & 27 & \\
\hline$I I I+I V$ & 6 & 14 & 20 & \\
\hline \multicolumn{4}{|c|}{$\begin{array}{l}\text { Recurrence or metastasis } \\
\text { after surgery }\end{array}$} & 0.028 \\
\hline No & 19 & 12 & 31 & \\
\hline Yes & 4 & 12 & 16 & \\
\hline \multicolumn{4}{|l|}{ Outcome } & 0.002 \\
\hline Alive & 22 & 13 & 35 & \\
\hline Death & 1 & 11 & 12 & \\
\hline
\end{tabular}

${ }^{\mathrm{a}}$ Fisher's exact test

adenocarcinoma patients. PD-L1 positivity in tumor cell membrane was significantly associated with higher stage $(p=0.047)$, recurrence or metastasis after surgery $(p=0.028)$, and fatal outcome $(p=0.002)$. On the other hand, PD-L1 positivity was not associated with gender, age at diagnosis.

\section{PD-L1 expression in TIMCs and clinico-pathological features}

Association between PDL-1 expression in TIMC and clinico-pathological factors are presented in Table 3. Overall, the extent of TIMCs infiltration was: absent in 0 patients, focal in 23 patients, mild in 17 patients, moderate in 6 patients and marked in 1 patient. PD-L1 expression in TIMCs was low (score $<5$ ) in 27 patients (57.4\%). Twenty patients (42.6\%) were considered as PD-L1 high (score $\geq 5$ ) in the TIMCs. Among the cases with PD-L1 high TIMCs, all patients showed positive expression in more than $5 \%$ of immune cells. There was a significant association between PD-L1 expression levels in TIMCs and recurrence or metastasis after surgery $(p=0.011)$, as well as PD-L1 expression levels and outcome of patients $(p=0.049)$. PD-L1 positivity in TIMCs was not significantly associated with gender $(p>0.999)$, age $(p=0.769)$, stage $(p=0.073)$.
Table 3 Association between PD-L1 expression in tumorinfiltrating mononuclear cells (TIMCs) and clinico-pathological factors $^{\mathrm{a}}$

\begin{tabular}{|c|c|c|c|c|}
\hline \multirow[t]{2}{*}{ Characteristic } & \multicolumn{3}{|c|}{$\%$ Positive tumor- infiltrating mononuclear cells } & \multirow[t]{2}{*}{$p$-value } \\
\hline & $\begin{array}{l}\text { Score }<5 \text { (low) } \\
(n=27,57.4 \%), n\end{array}$ & $\begin{array}{l}\text { Score } \geq 5 \text { (high) } \\
(n=20,42.6 \%), n\end{array}$ & $\begin{array}{l}\text { Total } \\
(n=47), n\end{array}$ & \\
\hline \multicolumn{4}{|l|}{ Gender } & \multirow[t]{3}{*}{$>0.999$} \\
\hline Male & 15 & 11 & 26 & \\
\hline Female & 12 & 9 & 21 & \\
\hline \multicolumn{4}{|l|}{ Age } & \multirow[t]{3}{*}{0.769} \\
\hline $65 \geq$ & 14 & 11 & 25 & \\
\hline $65<$ & 13 & 9 & 22 & \\
\hline \multicolumn{4}{|l|}{ Stage } & \multirow[t]{3}{*}{0.073} \\
\hline $1+\|$ & 19 & 8 & 27 & \\
\hline$I I I+I V$ & 8 & 12 & 20 & \\
\hline \multicolumn{4}{|c|}{$\begin{array}{l}\text { Recurrence or metastasis } \\
\text { after surgery }\end{array}$} & \multirow[t]{3}{*}{0.011} \\
\hline No & 19 & 12 & 31 & \\
\hline Yes & 8 & 8 & 16 & \\
\hline \multicolumn{4}{|l|}{ Outcome } & \multirow[t]{3}{*}{0.049} \\
\hline Alive & 23 & 12 & 35 & \\
\hline Death & 4 & 8 & 12 & \\
\hline
\end{tabular}

${ }^{\mathrm{a} F i s h e r ' s ~ e x a c t ~ t e s t ~}$

PD-L1 expression in malignant salivary gland tumors and survival time

The overall median follow-up of the cohort was 7.4 years, 12 patients died and 16 patients had recurrence or metastasis after surgery. PD-L1 positivity on tumor cell membrane and TIMCs both were associated with $\mathrm{OS}(p=0.002$ and $p=0.016$, respectively) (Fig. 2).

\section{Discussion}

This study demonstrated significant association between PD-L1 positivity in tumor cells and higher stage, recurrence or metastasis after surgery, fatal outcome or survival time in patients with malignant salivary gland tumors. In addition, significant association was also observed between PD-L1 expression levels in TIMCs and recurrence or metastasis after surgery or patient outcome. Therefore, we can assume that patients with PD-L1 positive malignant salivary gland tumors or TIMCs cannot be expected to show favorable prognosis, especially when conventional therapy or surgical operation is used as the treatment method. Hence, novel and advanced therapeutic approaches against locally advanced or metastatic malignant salivary gland tumors are needed to ensure favorable treatment outcome of patients. It was reported that, blocking the interactions between PD-1 and PD-L1 can inhibit antitumor 

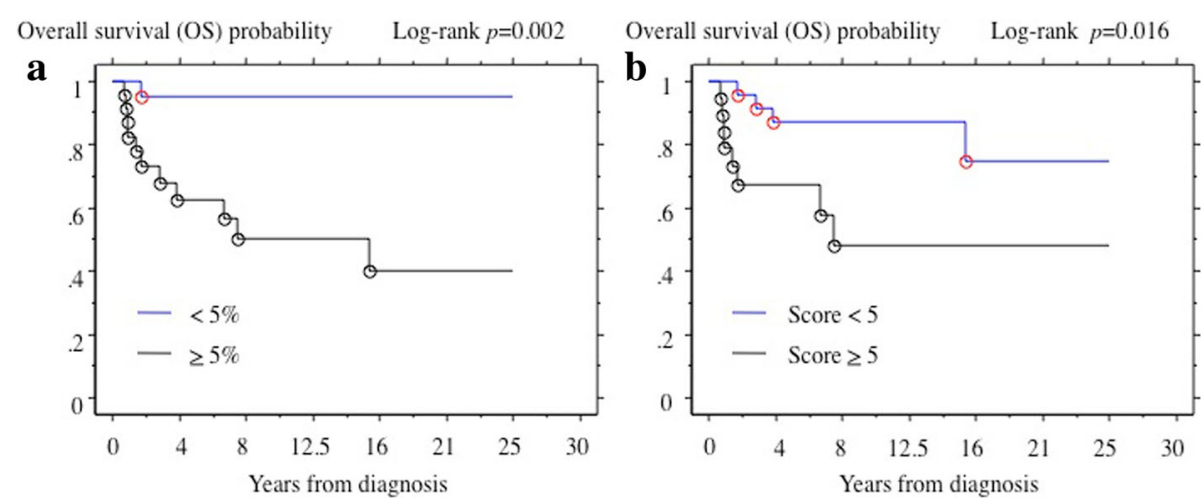

Fig. 2 PD-L1 expression in malignant salivary gland tumors. a Association of PD-L1 expression and OS in malignant salivary gland tumors. b Association of PD-L1 expression and OS in TIMCS. OS by PD-L1 positivity was estimated by Kaplan-Meier method. a PD-L1 positivity on tumor membrane (\% positive neoplastic cell). b PD-L1 Expression in TIMC (inflammatory cell store)

immunity, enhance T-cell-mediated immune function and promote antitumor activity of therapeutic agents in preclinical models and in vitro [20]. Brahmer et al. showed the efficacy of anti-PD-L1 antibody (BMS93655) in his multicenter phase 1 trial study with patients with advanced cancer, including non-small-cell lung cancer, melanoma and renal-cell cancer [20]. Recently, anti-PD-1 monoclonal antibody (nivolumab) is considered as a new therapeutic option for the treatment of unresectable malignant melanoma [21]. Moreover, some clinical studies that evaluated the safety and efficacy of nivolumab in patients with advanced cancer showed encouraging results [21-24]. However, higher PD-L1 expression in tumor cells is not always associated with unfavorable outcome $[25,26]$.

Until now, there were no available reports that indicated any relationship between PD-L1 expression and clinical outcomes in malignant salivary gland tumor patients. To our knowledge, this is the first study that demonstrated the association between PD-L1 expression in tumor cells or TIMCs with recurrence or metastasis after surgery, fatal outcome and shorter OS in patients with malignant salivary gland tumors treated by surgical operation. We could detect PD-L1 expression both in tumor cells and TIMCs. The detail mechanisms of PDL1 expression in tumor cells or TIMCs are still unknown. It is reported that, Natural killer cells as well as T-cells expresses cytokines such as interferon- $\gamma$ (IFN$\gamma)$, tumor necrosis factor- $\alpha$ (TNF- $\alpha$ ) and interleukin-2 (IL-2) which in turn can induce PD-L1 expression on surrounding immune and tumor cells when T-cells recognize antigen and become activated [27]. TIMCs also have an important role in induction of PD-L1 expressions, and various cytokines derived from TIMCs promotes tumor growth as well as impairs antitumor immune responses. The expression mechanisms of PDL1 must be complicated with different circumstances involved; however, the extent of TIMCs could be an important predictive factor for anti-PD-1 monoclonal antibody therapy including nivolumab [21]. In this study, we found high extent of TIMCs, as well as high PD-L1 expression in both tumor cells and TIMCs. Nivolumab has just got marketing approval as a drug for the treatment of unresectable malignant melanoma, and it might also be effective for locally advanced or metastatic malignant salivary gland tumors [21]. Further in vitro, in vivo and clinical studies with anti-PDL-1 antibody (BMS93655) against salivary gland tumors might also generate favorable results.

Our study is a retrospective analysis of PD-L1 expression and we have only analyzed 47 cases of malignant salivary gland tumors. Further prospective studies are needed to understand the role of PD-L1 expression more precisely in immune cells as a predictive and prognostic biomarker in malignant salivary gland tumors.

\section{Conclusion}

This is the first study that demonstrated the association between PD-L1 positive expression and clinical stage, recurrence or metastasis after surgery and survival time of patients with malignant salivary gland tumors. Our data also showed significant association between PD-L1 expression levels in TIMCs and recurrence or metastasis after surgery or patient outcome.

\section{Abbreviations}

DC: dendritic cells; FFPE: Formalin-Fixed Paraffin-Embedded; IFN-Y: InterferonY; Ig: Immunoglobulin; IL-2: Interleukin-2; OS: Overall survival; PBS: Phosphatebuffered saline; PD-1: Programmed death-1; PDL1: Programmed death ligand 1; TIMC: Tumor-infiltrating mononuclear cell; TNFr: TNF receptor; TNF-

a: Tumor necrosis factor-a

\section{Acknowledgements}

Not applicable 


\section{Funding}

This study was supported in part by a Grant-in-Aid from the Japanese Ministry of Education, Science and Culture (Grant no. 24593034). Funding body had no contribution in designing the study, data collection, interpretation or analysis of data, or writing the manuscript.

\section{Availability of data and materials}

The datasets used and analyzed during the current study available from the corresponding author on reasonable request.

\section{Authors' contributions}

$\mathrm{KH}$ was involved in the study design, data analysis, and writing of the manuscript. TF carried out the immunohistochemical studies, data collection and evaluation, and assisted in manuscript writing. YU revised and edited the manuscript. All the authors read and approved the final version of the manuscript.

\section{Authors' information}

$\mathrm{KH}$ is assistant professor, TF is academic researcher and UY is professor in Department of Oral and Maxillofacial Surgery, Yamaguchi University Graduate School of Medicine, Ube, Japan.

\section{Ethics approval and consent to participate}

Institutional review board (IRB) approval from the ethical committee of the Yamaguchi University Hospital was obtained for this study (Ref H26-179). As this study was retrospective, informed consent was waived by the IRB.

\section{Consent for publication}

Not applicable

\section{Competing interests}

The authors declare that they have no competing interests.

\section{Publisher's Note}

Springer Nature remains neutral with regard to jurisdictional claims in published maps and institutional affiliations.

Received: 21 August 2015 Accepted: 29 January 2018

Published online: 06 February 2018

\section{References}

1. Speight PM, Barrett AW. Salivary gland tumours. Oral Dis. 2002;8:229-40.

2. Carvalho AL, Nishimoto IN, Califano JA, Kowalski LP. Trends in incidence and prognosis for head and neck cancer in the United States: a site-specific analysis of the SEER database. Int J Cancer. 2005;114:806-16.

3. Kaplan MJ, Johns ME, Cantrell RW. Chemotherapy for salivary gland cancer Otolaryngol Head Neck Surg. 1986;95:165-70.

4. Belani CP. Preliminary experience with chemotherapy in advanced salivary glands neoplasms. Med Pediat Oncol. 1988;16:197-202.

5. Noh JM, Ahn YC, Nam H, Park W, Baek CH, Son Yl, Jeong HS. Treatment results of major salivary gland cancer by surgery with or without postoperative radiation therapy. Clin Exp Otorhinolaryngol. 2010;3:96-101.

6. Licitra L, Cavina R, Grandi C, Palma SD, Guzzo M, Demicheli R, Molinari R. Cisplatin, doxorubicin and cyclophosphamide in advanced salivary gland carcinoma: a phase II trial of 22 patients. Ann Oncol. 1996:7:640-2.

7. Caballero M, E Sosa A, Tagliapietra A, Grau JJ: Metastatic adenoid cystic carcinoma of the salivary gland responding to cetuximab plus weekly paclitaxel after no response to weekly paclitaxel alone. Head Neck 2013 35: $52-54$

8. Chambers CA, Allison JP. Costimulatory regulation of T cell function Curr Opin Cell Biol. 1999:11:203-10.

9. Pardoll DM. Spinning molecular immunology into successful immunotherapy. Nat Rev Immunol. 2002;2:227-38.

10. Dong H, Zhu G, Tamada K, Chen L. B7-H1, a third member of the B7 family, co-stimulates T-cell proliferation and interleukin-10 secretion. Nat Med. 1999:5:1365-9.

11. Tseng SY, Otsuji M, Gorski K, Huang X, Slansky JE, Pai SI, Shin T, Pardoll DM, Tsuchiya H. B7-DC, a new dendritic cell molecule with potent costimulatory properties for T cells. J Exp Med. 2001;193:839-46.

12. Ohigashi $Y$, Sho M, Yamada Y, Tsurui Y, Hamada K, Ikeda N, Mizuno T, Yoriki R, Kashizuka H, Yane K, Tsushima F, Otsuki N, Yagita H, Azuma M, Nakajima
Y. Clinical significance of programmed death-1 ligand-1 and programmed death-1 ligand-2 expression in human esophageal cancer. Clin Cancer Res. 2005;11:2947-53.

13. Yamazaki T, Akiba H, Iwai H, Matsuda H, Aoki M, Tanno Y, Shin T, Tsuchiya H, Pardoll DM, Okumura K, Azuma M, Yagita H. Expression of programmed death 1 ligands by murine T cells and APC. J Immunol. 2002;169:5538-45.

14. Yuan $Y$, He $Y$, Wang $X$, Zhang H, Li D, Feng Z, Zhang G. Investigation on the effects of soluble programmed death-1 (sPD-1) enhancing anti-tumor immune response. J Huazhong Univ Sci Technolog Med Sci. 2004;24:531-4.

15. Thompson RH, Gillett MD, Cheville JC, Lohse CM, Dong H, Webster WS, Krejci KG, Lobo JR, Sengupta S, Chen L, Zincke H, Blute ML, Strome SE, Leibovich BC, Kwon ED. Costimulatory B7-H1 in renal cell carcinoma patients: Indicator of tumor aggressiveness and potential therapeutic target. Proc Natl Acad Sc. 2004;101:17174-9.

16. Wu C, Zhu Y, Jiang J, Zhao J, Zhang XG, Xu N. Immunohistochemical localization of programmed death-1 ligand-1 (PD-L1) in gastric carcinoma and its clinical significance. Acta Histochem. 2006:108:19-24.

17. Nakanishi J, Wada Y, Matsumoto K, Azuma M, Kikuchi K, Ueda S. Overexpression of B7-H1 (PD-L1) significantly associates with tumor grade and postoperative prognosis in human urothelial cancers. Cancer Immunol Immunother. 2007:56:1173-82.

18. Nomi T, Sho M, Akahori T, Hamada K, Kubo A, Kanehiro H, Nakamura S, Enomoto K, Yagita H, Azuma M, Nakajima Y. Clinical significance and therapeutic potential of the programmed death-1 ligand/programmed death-1 pathway in human pancreatic cancer. Clin Cancer Res. 2007;13: 2151-7.

19. Hino R, Kabashima K, Kato Y, Yagi H, Nakamura M, Honjo T, Okazaki T, Tokura Y. Tumor cell expression of programmed cell death-1 ligand 1 is a prognostic factor for malignant melanoma. Cancer. 2010;116:1757-66.

20. Brahmer JR, Tykodi SS, Chow LQ, Hwu WJ, Topalian SL, Hwu P, Drake CG, Camacho LH, Kauh J, Odunsi K, Pitot HC, Hamid O, Bhatia S, Martins R, Eaton K, Chen S, Salay TM, Alaparthy S, Grosso JF, Korman AJ, Parker SM, Agrawal S, Goldberg SM, Pardoll DM, Gupta A, Wigginton JM. Safety and activity of anti-PD-L1 antibody in patients with advanced cancer. N Engl J Med. 2012:366:2455-65.

21. Brahmer JR, Drake CG, Wollner I, Powderly JD, Picus J, Sharfman WH, Stankevich E, Pons A, Salay TM, McMiller TL, Gilson MM, Wang C, Selby M, Taube JM, Anders R, Chen L, Korman AJ, Pardoll DM, Lowy I, Topalian SL. Phase I study of single-agent anti-programmed death-1 (MDX-1106) in refractory solid tumors: safety, clinical activity, pharmacodynamics, and immunologic correlates. J Clin Oncol. 2010;28:3167-75.

22. Topalian SL, Hodi FS, Brahmer JR, Gettinger SN, Smith DC, McDermott DF, Powderly JD, Carvajal RD, Sosman JA, Atkins MB, Leming PD, Spigel DR, Antonia SJ, Horn L, Drake CG, Pardoll DM, Chen L, Sharfman WH, Anders RA Taube JM, McMiller TL, Xu H, Korman AJ, Jure-Kunkel M, Agrawal S, McDonald D, Kollia GD, Gupta A, Wigginton JM, Sznol M. Safety, activity, and immune correlates of anti-PD-1 antibody in cancer. N Engl J Med. 2012;366:2443-54.

23. Motzer RJ, Rini BI, McDermott DF, Redman BG, Kuzel TM, Harrison MR, Vaishampayan UN, Drabkin HA, George S, Logan TF, Margolin KA, Plimack ER, Lambert AM, Waxman IM, Hammers HJ. Nivolumab for Metastatic Renal Cell Carcinoma: Results of a Randomized Phase II Trial. J Clin Oncol. 2015;33: 1430-7.

24. Rizvi NA, Mazières J, Planchard D, Stinchcombe TE, Dy GK, Antonia SJ, Horn L, Lena H, Minenza E, Mennecier B, Otterson GA, Campos LT, Gandara DR Levy BP, Nair SG, Zalcman G, Wolf J, Souquet PJ, Baldini E, Cappuzzo F, Chouaid C, Dowlati A, Sanborn R, Lopez-Chavez A, Grohe C, Huber RM, Harbison CT, Baudelet C, Lestini BJ, Ramalingam SS. Activity and safety of nivolumab, an anti-PD-1 immune checkpoint inhibitor, for patients with advanced, refractory squamous non-small-cell lung cancer (CheckMate 063): a phase 2, single-arm trial. Lancet Oncol. 2015;16:257-65.

25. Bellmunt J, Mullane SA, Werner L, Fay AP, Callea M, Leow JJ, Taplin ME, Choueiri TK, Hodi FS, Freeman GJ, Signoretti S. Association of PD-L1 expression on tumor-infiltrating mononuclear cells and overall survival in patients with urothelial carcinoma. Ann Oncol. 2015;26:812-7.

26. Schalper KA, Velcheti V, Carvajal D, Wimberly H, Brown J, Pusztai L, Rimm DL. In situ tumor PD-L1 mRNA expression is associated with increased TILs and better outcome in breast carcinomas. Clin Cancer Res. 2014;20:2773-82.

27. Ritprajak P, Azuma M. Intrinsic and extrinsic control of expression of the immunoregulatory molecule PD-L1 in epithelial cells and squamous cell carcinoma. Oral Oncol. 2015:51:221-8. 